
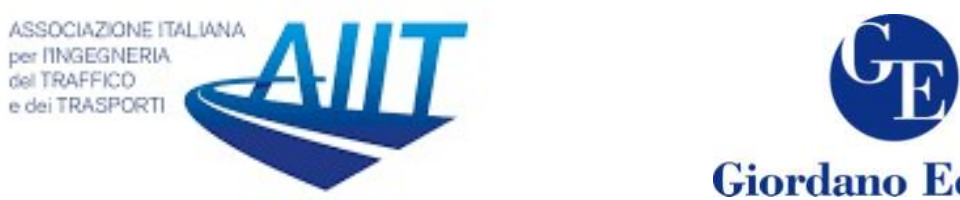

Giordano Editore

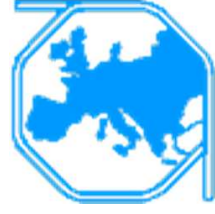

\title{
A new proposal for fare differentiation for the Integrated Time Ticket in the city of Rome
}

\author{
Alessio Marabucci ${ }^{1 *}$ \\ ${ }^{1}$ Roma Tre University, ATAC
}

\begin{abstract}
This work analyses the possibility for the Municipality of Rome and ATAC, the company that manages Local Public Transport (LPT) in the capital, to introduce a tariff differentiation for ITT (Integrated TimeTicket), i.e. two separate fares for the ticket, with a peak-load scheme.

These tariff models are very widespread in Northern Europe, but also in Italy the redefinition of tariff offers is gaining ground.

The concept behind the tariff discrimination refers to the possibility for the monopolist, who knows the demand function of the reference market, to be able to offer goods and services at different prices, depending on the range of users and the different price elasticity of demand.

In this study the effects of price differentiation are quantified economically through appropriate demand elasticity and, under specific assumptions, it is shown that price differentiation can both increase sales revenues and ticket sales.
\end{abstract}

Keywords: fare discrimination, natural monopoly, elasticity of demand.

\section{Fundamentals of price discrimination}

The demand for transport services fluctuates periodically, i.e. moments of "high demand" alternate with phases of "low demand", so it is necessary to dimension transport services correctly in order to be able to offer service levels adapted to the various cyclical phases, so it is necessary to orientate users in order to use the transport system as a whole in the most correct and efficient way possible through the choice of an appropriate tariff system.

Tariffs should be set in such a way that users do not reduce their level of usefulness of the journey and, at the same time, allow the costs necessary to build adequate infrastructure to meet demand to be contained.

\footnotetext{
* Corresponding author: Alessio Marabucci (alessiomarabucci@gmail.com)

The author would like to thank the ATAC company for providing the information useful for the drafting of this work, in particular the thanks go to Dr. Stefano Guadalupi, Director of Planning, Control and Service Contracts for his availability.
} 
In the case of local public transport services, peak and off-peak demand phases alternate on the same day, so it is reasonable to assume that during part of the day there will be a proportion of users willing to travel only during peak phases, and therefore willing to pay a higher price, compared to another proportion of users who can use public transport during the rest of the day, thus showing a willingness to pay less.

On the basis of this theory, different prices can be outlined for LPT service during the average day (typically the working day), and each price (or rather, the fare) should be commensurate with the responsiveness of demand expressed by users to price changes in the fares themselves (hypothesis of "rigid" and "elastic" demand).

In particular, we will focus on the Integrated Time Ticket (ITT), whose current rate is 1.5 euros and is valid for 100 minutes from the first stamping, allowing you to travel on all public transport operating in the Lazio tariff system.

\section{Theoretical framework and empirical review}

The first step is to assess the demand for LPT, which can be approximated by counting passengers, or by reconstructing the journeys made by public transport (recreating the origin/destination matrices; finally, other ways of estimating LPT demand include the procedure that transforms the volumes of tickets sold into passengers through the application of special coefficients, estimated from interviews conducted on board vehicles with users holding an appropriate ticket.

All these methods to estimate the demand for public transport and do not always reflect the true magnitude of the phenomenon, so another proxy for demand may be the amount of tickets sold at a given time (e.g. one year), even if this entity is not without limitations ${ }^{1}$.

In the literature there are several methodological practices followed for the analysis of LPT demand, starting with the studies of Bly and Webster (1980), Goodwin and Williams (1985), McKenzie and Goodwin (1986) and de Rus (1990) and ending, among others, with the work of Matas (2004).

In particular in the last 25 years it is possible to make a distinction in the work related to the estimation of LPT demand, at least from a methodological point of view.

In this regard, in fact, three main groups can be recognized: the first group includes work adopting Apparently Unrelated Regression (SUR) approaches, such as the studies of Fitzroy and Smith (1994, 1999) and Matas (2004); the second group concerns studies based on the analysis of historical series, such as the contributions of Tegnér et al (1998) and Garcia-Ferrer et al. (2004, 2006); finally, studies focusing on large geographical areas or individual companies respectively, using panel estimation techniques, such as the work of Dargay and Hanly (2002), Bresson et al. (2003) or Abrate et al. (2007).

Another distinguishing factor is the type of data used, so that models using aggregated information and those based on micro-data can be recognised. In particular, we recall the contributions of Goodwin (1992), Hanly and Dargay (1999), Balcombe et al. (2004), Littman (2004) and Paulley et al. (2006). Other studies, such as those by Nijkamp and Peppings (1998, pp. 3-4) underline how the possible aggregated nature of the model, typical of historical series, determines values more contained and less precise than the estimated parameters, while the contributions of Bresson et al. (2003, p. 606) show how

\footnotetext{
${ }^{1}$ However, ticket quantity data can be used to measure public transport demand and to assess the effect of a change in ticket or season ticket prices on the quantity sold, so it is necessary to model a demand function and a supply function.
} 
the historical series approach provides the most interesting and robust results compared to transversal analyses.

Finally, other problems concern the correct specification of transport demand estimation models in general and LPT in particular; the problem of the exclusion of regressor variables adopted may lead to distortions in estimates, so that some essential variables (including control variables) need to be included in the model for correct specification, as pointed out by Holmgrem (2007, p. 1033).

In the Italian case, an interesting analysis was successfully conducted by Bigerna and Polinori (2016), who conducted a study on the elasticity of ticket demand in the city of Perugia at rate of 0.5 .

The comparison with the existing literature on the subject shows that the numerous results do not always agree on the sign and intensity of connections.

The study produced by Preston (1998) identifies a very wide range of values, for the type of data used and for the territorial characteristics of the regions surveyed ${ }^{2}$.

In the present case, the price elasticity of ITT (highly significant) falls within the range of the values available in the literature; the short-term estimates are -0.96 for road transport and -0.45 for rail transport.

The results obtained by authors such as Dargay and Hanly (2002, p. 88) for road transport in British non-metropolitan areas show values of -0.49 ; other works, such as Matas (2004, p. 204) for the Madrid area, and De Rus (1990, p. 204) for the Madrid area. 195) for small and medium-sized Spanish cities, respectively, short-term values of -0.21 and parameters between -0.10 and -0.39 , while the studies of Bresson (et al. 2003, p. 620) show, for some regions of France, short-term elasticity parameters of -0.40 .

In general Goodwin (1992) concludes that it would make sense to consider the static elasticity figure of -0.3 in Webster magazine and Bly (1980) as a reasonable figure for effects within the first year; that the effect after about four years (the "medium term") would be -0.55 ; rising to -0.65 over a period of about a decade. Overall, it is clear that long-term elasticities are between 50 per cent and three times higher than short-term elasticities.

These values are in line with the parameter estimated in the Roman case, equal to -0.49 , so that the terms of comparison with other European realities are comforting and strengthen the validity of the result obtained.

In the more specific case of the estimate of the elasticity of the demand "peak" / "load" should be mentioned the study produced by Horn af Rantzien and Rude for the Stockholm case (Horn af Rantzien, Rude, 2014).

In fact, according to the authors, dividing the demand for local public transport in the Swedish capital into "peak" and "off peak" (or "load") demand bands, it is possible to estimate specific elasticities using econometric techniques.

The peak period elasticities range from -0.14 to -0.20 while the off-peak period elasticities range from -0.16 to -0.31 , which are slightly lower than those quantified in this paper, but the difference between peak and off-peak demand elasticities, i.e. the possibility of tariff discrimination by time band, remains evident.

\footnotetext{
${ }^{2}$ However, similar work also shows that there are common models concerning both the elasticity values for the different types of tickets and, excluding individual travel tickets, the ratios between the elasticity of demand expressed as the number of tickets rather than the number of trips.
} 


\section{A new fare proposal for the Integrated Time Ticket in Rome and Lazio}

We now briefly illustrate the current tariff system in force in Lazio, where there is the Metrebus, an integrated tariff system that differentiates the territory of Lazio as an area stratified at concentric levels increasingly distant from Rome (which occupies the central zone).

Each zone corresponds to a different system of fares and types of tickets, so much so that Metrebus is similar to a container in which the fare revenue from all tickets sold in the territory and relating to the LPT service offered by three distinct entities: ATAC, Co.Tra.L. (regional public transport) and Trenitalia (regional rail services).

The fare allocation system provides for a share of the total revenue to be collected by ATAC, while two smaller shares belong to Co.Tra.L and Trenitalia according to a specific allocation mechanism.

Within the Metrebus system the Integrated Time Ticket (ITT) represents one of the most used (and sold) tickets within the Metrebus system, it is therefore a widely used ticket and therefore it can be assumed that the price of this ticket will be differentiated according to the part of the day, i.e. peak and soft.

As can be seen from the table for the year 2019, it is expected to sell about 92.4 million ITT, which will generate, net of VAT and in relation to the ATAC share of Metrebus ( $86 \%$ of the so-called "Metrebus Roma" titles, like ITT), about 108 million euros of total revenues, so ITT is one of the most important titles in the financial statements of the company that manages public transport in Rome.

The data used in the analysis model, both those referring to 2019 and those referring to 2020, are the result of an estimate by the writer, since at the time of writing this work has not yet completed the year, in detail it is assumed that the number of ITT sold for the year 2019 is about $2 \%$ higher than the previous year.

Table 1: ITT sales volumes and fares

\begin{tabular}{lrr} 
& \multicolumn{1}{c}{$2019 *$} & $2020 * *$ \\
\cline { 2 - 3 } curre nt s cenario (ITT) & 92.456 .793 & 92.504 .053 \\
\hline volumes (units) & 1,5 & 1,5 \\
Fare (euros) & $10 \%$ & $10 \%$ \\
VAT & $86 \%$ & $86 \%$ \\
Atac Metrebus share & 108.426 .603 & 108.482 .026 \\
\hline \multicolumn{3}{l}{} \\
\hline Net income Atac (euros) & \\
\hline$*$ the 2019 ITT volumes are provisional (budget) & \\
$* *$ the ITT volumes for 2020 are the result of an estimate
\end{tabular}

Source: own elaborations

If it were decided to propose a different tariff structure for the security in question, with a distinction between a 'peak' and an 'off-peak' tariff, this could have an effect both in economic terms and in terms of increased demand served.

ITT's two separate tariffs could amount to:

- EUR 2 (compared to the current EUR 1,5, with an increase of EUR 0,5), defined as the ITT 'peak' tariff;

- EUR 1,3 (compared to the current EUR 1,5, with a reduction of EUR 0,2), the "off peak" tariff.

These pricing schemes are widely used in Northern Europe, in cities such as London for example, and make it possible to discriminate between two different levels of public transport "user price", with the aim of both stimulating demand (as "soft-hour" fares are lower than peak-hour fares) and optimising revenue from ticket sales. 
In order to define these fares, it was first necessary to estimate the elasticity of ITT's demand in relation to its fare.

The evolution of ITT's sales volumes shows that from an average of approximately 106 million tickets sold in the two-year period 2010-2011, it rose to 97 million in 2012 (remember that the previous tariff package became operational mid-year), before falling to a value close to 93 million in 2013.

The drop in sales is largely due to the general increase in all Metrebus ticket prices in May 2012, when ticket prices rose from $€ 1$ to $€ 1.5$.

The difference between the sales volumes in the two years prior to the last tariff adjustment and the two years after, in terms of sales volumes of ITT stock is -19.8 million, or $-9.4 \%$, compared to a tariff increase of $50 \%$ (from 1 euro to 1.5 euro).

From these two values it is possible to estimate an elasticity, or more precisely an arc elasticity, equal to $-0.49^{3}$.

From the precise value of the "average" elasticity (as it refers to the entire demand for ITT), under certain assumptions, two different elasticities can be deduced, one for the "peak" type and the other for the "off-peak" type.

Apart from this distinction, since the measured elasticity of the ITT, in absolute terms, is less than one, raising the price of the security, even though it loses a fraction of the sales volumes, there would be an increase in overall revenues from the sale of travel securities, precisely because the elasticity of the BIT is still sufficiently low (less than one unit).

\section{Definition of the 'peak' and 'soft' time bands and the segmentation of demand}

It can be assumed that the "peak" band may be between 7:00 and 10:00 in the morning and between 16:00 and 19:00 in the afternoon, for a total of 6 hours (out of 18 hours of daily service, which becomes 20 at weekends), so the "off peak" band includes the remaining hours of the day.

If the 'peak'/'off peak' tariff differentiation described here were applied, there would be a (negative) change in peak ITT sales volumes (due to the increase in the tariff to EUR 2) and a (positive) change in off peak ITT sales volumes (due to the reduction in the tariff to EUR 1,3). The change in the quantities of ITT sold after the proposed tariff increase is commensurate with the extent of the elasticity of demand.

It has been found that the (average) elasticity of ITT is $-0,49$, therefore the concept of rigid ('peak') and elastic ('off-peak') demand has been introduced, so that it is plausible to assume a lower coefficient of elasticity for the share of LPT users in the peak time slot and a correspondingly higher coefficient of elasticity for the share of LPT users in the soft time slot ('off peak'); these elasticities can be estimated, as a first approximation, at 0.24 (half of the average) and -0.65 (about one third higher than the average) respectively.

These values were first obtained by dividing the current sales volume of ITT into the two 'peak' and 'off peak' tranches (i.e. $40 \%$ and $60 \%$ above), to which the respective price elasticities will then be applied (according to the new tariffs).

\footnotetext{
${ }^{3}$ In other studies (see Marabucci, 2016), using econometric estimation techniques, it was found that the elasticity of ITT to its (real) fare was -0.45 , a value in line with that measured in this work, and in turn consistent with the elasticity values of tickets estimated in similar studies.
} 
The two percentages have been deducted from the number of validations at access points to Rome's underground stations (lines A, B/B1 and C) per time slot ${ }^{4}$.

The problem to be addressed is the estimation of two separate elasticities from a single average parameter, i.e. 0.49 ; this value can be interpreted as a weighted average value of the elasticity, i.e:

$$
\varepsilon=W_{1} \text { epeak }+W_{2} \text { eoff peak }
$$

here $\varepsilon_{\text {peak }}$ represents the elasticity of the "peak" user, $\varepsilon_{\text {off peak }}$ represents the elasticity of the "off peak" user and $w_{1}$ and $w_{2}$ are the respective weighting factors.

Now the term $\varepsilon$ is known, while the values to the right of the equality are unknown and in some way they have to be estimated.

From studies conducted by ATAC it turns out that the average percentage hourly weight on the whole day of the validations in the middle hourly band of peak is equal to approximately $8 \%$ on the lines $\mathrm{A}$ and $\mathrm{B}$, while the correspondent weight of the middle hourly band of soft (middle hourly) is equal to approximately the half.

The proportion between the two percentages can be assumed as an indicator of how much the incidence of the average peak hour is greater than that of the soft hour, for a factor equal to 2 , so the reciprocal of this value, that is 0.5 , can be used to estimate the proportion, with respect to the average elasticity $(-0.49)$, of the "peak" demand, which is equal to -0.245 (or half of the average value).

About the weights $\mathrm{W}_{1}$ and $\mathrm{W}_{2}$ we can refer to the two quotas of $40 \%$ and $60 \%$ estimated in the way described in the text, so that now in the expression (1) only one term remains unknown, that is $\varepsilon$ off peak, which must necessarily assume the only value compatible with the data of the problem, that is:

$$
0,49=0,40 \% \times 0,245+60 \% \times \varepsilon_{o f f} p e a k(2)
$$

from which it follows that $0,49=0,40 \% \times 0,245+60 \% \times$, $\varepsilon_{\text {off peak }}$ and, reformulating the expression by explicitly stating, $\varepsilon_{\text {off peak }}$, we obtain the sought estimate of the elasticity of the demand "off peak", that is eoff peak $=[0,49-(0,4)(0,245)] / 0,6$, that is about 0,65 (in absolute value $)^{5}$.

These values are not entirely random, as the weighted average elasticity "peak" and "off peak", given these sales volumes, must generate the measured value of $-0.49^{6}$.

Changes in the proportionality parameter between peak and off-peak demand elasticities are directly reflected in the values assumed by the two different types of elasticities, with effects on the final results, so that future investigations could lead to more accurate estimates of the elasticity parameters.

\footnotetext{
${ }^{4}$ Validation in metro stations is currently the only data measured on the influx of passengers to Rome's public transport system, as on board surface vehicles (trams, trolleybuses and buses) the number of validations is very low (due to the low propensity of users to validate their subscriptions), so it would not be reliable for the quantification of public transport demand.

${ }^{5}$ The value of 0.65 is less than one, so we are in the demand function section where demand itself is inelastic and, maintaining the linear demand hypothesis, in theory it would be possible to further increase the ticket price, losing on the one hand a share of sales but increasing overall turnover.

${ }^{6}$ Irrespective of these distribution shares, it can be assumed that users using LPT at peak times will show a relatively less responsive demand to changes in ticket prices, similarly it can be assumed that the share of users concentrating their movements in the rest of the day presents a relatively more flexible demand, so that in the first case ('peak'), there is a very limited contraction in demand (sales volumes), while in the second case ('off peak'), following a reduction in prices, there is a more substantial increase in volumes.
} 


\section{Effects of fare discrimination on ATAC revenues and impacts on users}

The development of the impact of this fare package in terms of revenues from the sale of tickets (ATAC's share) can be carried out by applying the respective ITT "peak" (2 euros) and "off peak" (1.3 euros) fares, subject to the separation of VAT (10\%) and the application of the apportionment percentage of the Metrebus Roma system (86\%).

The estimate leads to the conclusion that a different fare structure for the ITT such as that presented in this work, given the values of elasticity and the distribution between "peak" and "off peak" demand, would allow ATAC to achieve a net incremental revenue of approximately 5.9 million euros on the basis of the 2019 sales forecasts (for 2020 the value is similar, see table 4).

\section{Table 2: ITT's peak and off peak differentiation}

\begin{tabular}{lrr}
\cline { 2 - 3 } Diffe re ntiate d tariff sys te m & 2019 & 2020 \\
\cline { 2 - 3 } ("peak", "off peak") & & \\
\hline "Peak" volumes (\%) & $40,0 \%$ & $40,0 \%$ \\
"Off peak" volumes (\%) & $60,0 \%$ & $60,0 \%$ \\
\hline & & \\
\hline "Peak" elasticity & $(0,246)$ & $(0,246)$ \\
"Off peak" elasticity & $(0,654)$ & $(0,654)$ \\
\hline & & \\
\hline "Peak" (units) volumes (ante-elasticity) & 36.982 .717 & 37.001 .621 \\
"Off peak" (units) volumes (ante-elasticity) & 55.474 .076 & 55.502 .432 \\
\hline ITT totale volumes (units) & 92.456 .793 & 92.504 .053 \\
\hline
\end{tabular}

Source: own elaborations

An increase in the ITT tariff in the "peak" band from $€ 1.5$ to $€ 2$ million would lead to a reduction in sales volumes of around $€ 3$ million, while a reduction in the "off peak" band from $€ 1.5$ to $€ 1.3$ million would lead to an increase in sales volumes of around $€ 4.8$ million, with a net positive balance of around $€ 1.8$ million (see Table 3 ), matched by a net increase in revenues of around $€ 5.9$ million (see Table 4).

Tables 3 and 4: fare differentiation and ITT's sales volumes/revenues

\begin{tabular}{|c|c|c|}
\hline & \\
\hline & 2019 & 2020 \\
\hline "Peak" fare (euros) & 2,0 & 2,0 \\
\hline "Off peak" fare (euros) & 1,3 & 1,3 \\
\hline Actual fare (euros) & 1,5 & 1,5 \\
\hline$\Delta$ "peak" fare (euros) & 0,5 & 0,5 \\
\hline$\Delta$ "off peak" fare (euros) & $(0,2)$ & $(0,2)$ \\
\hline $\begin{array}{l}\Delta \text { "peak" volumes (elasticity effect, units) } \\
\text { (a) }\end{array}$ & $(3.030 .568)$ & $(3.032 .117)$ \\
\hline$\Delta$ "off peak" volumes (elasticity effect, units) & 4.836 .786 & 4.839 .259 \\
\hline "Peak" volume (post elasticity, units) & 33.952 .149 & 33.969 .504 \\
\hline "Pff peak" volumes (post elasticity, units) & 60.310 .862 & 60.341 .690 \\
\hline ITT total volumes (post elasticity, units) & 94.263 .011 & 94.311 .195 \\
\hline ITT total volumes "ante" fares differentiation & 92.456 .793 & 92.504 .053 \\
\hline "ante" / "post" volumes differential & 1.806 .218 & 1.807 .142 \\
\hline
\end{tabular}

\begin{tabular}{lrr}
\cline { 2 - 3 } Revenues from the sale of travel tickets & $\mathbf{2 0 1 9}$ & $\mathbf{2 0 2 0}$ \\
\cline { 2 - 3 } & & \\
\hline "Peak" Atac net revenue (euros) & 53.088 .815 & 53.115 .952 \\
"Off peak" Atac net revenue (euros) & 61.297 .767 & 61.329 .100 \\
\hline Atac net revenue (post fare differentiation) & 114.386 .582 & 114.445 .052 \\
\hline & & \\
\hline Atac net revenue (post, euros) & 114.386 .582 & 114.445 .052 \\
Atac net revenue (ante, euros) & 108.426 .603 & 108.482 .026 \\
\hline Atac net revenue differential (euros) & 5.959 .980 & 5.963 .026 \\
\hline
\end{tabular}

Source: own elaborations

The differentiation of the ITT fare proposed has a greater impact on occasional users of public transport, since those who use LPT to systematically make their journeys, 
especially home-work and home-study journeys (and who travel at times identified as "peak"), in the vast majority of cases are in possession of a subscription (or monthly or annual), so that they will not reasonably suffer the effects of this fare change ${ }^{7}$.

The next step is to estimate an entire demand curve for the BIT separately for the two types of "peak" and "off peak" demand.

In fact, starting from the elasticity of demand for the two types of users, it is possible to estimate the relative demand curves (linear for simplicity), since it is known that the elasticity of demand, expressed in this form:

$$
\varepsilon=\frac{d Q}{d P} \frac{P}{Q}(3)
$$

Equivalently, the (3) can also be expressed as $\varepsilon=\mathrm{dQ} / \mathrm{Q} / \mathrm{dP} / \mathrm{P}$, a formulation that makes it possible to assess the elasticity of the sales volumes of the ITT with respect to the fare in an area around the fare variation.

The (3) can be used to calculate the two linear (inverse) demand functions:

- peak" demand: Fare $=10,14$ - 0,239 x ITT volumes;

- off peak" demand: Fare $=3,03$ - 0,033 x ITT volumes.

The term A intercepts the generic (inverse) demand function $\mathrm{P}=\mathrm{A}-\mathrm{bQ}$ and represents, as is known from economic theory, the choke price, i.e. the maximum price above which no unit of the good/service in question will be sold, as already seen.

In the two cases "peak" and "off peak", it can be seen from the expressions of the two demand functions that the first has a higher choke price (about 10 euros) and a higher slope, as is normal given the greater rigidity of the elasticity; on the contrary, in the second case ("off peak") the choke price is lower (about 3 euros) and a lower slope, so the demand curve is (relatively) flatter ${ }^{8}$.

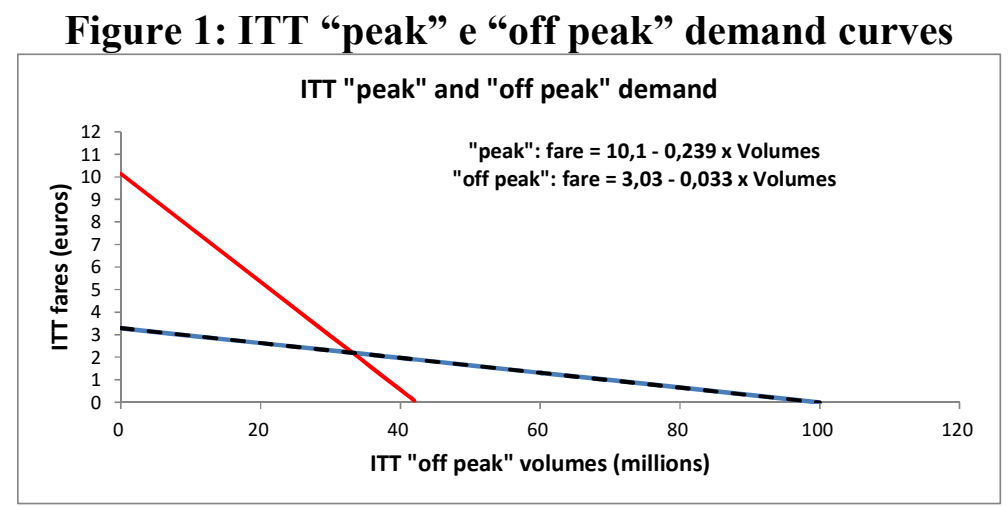

Source: own elaborations

\footnotetext{
${ }^{7}$ It is highly probable that the share of users affected by this measure is mainly composed of tourists or occasional users (city users), who by definition are less sensitive to price (therefore have a lower elasticity), and therefore are willing to pay a higher price to make their movements in the time slots referred to as "peak".

${ }^{8}$ It is obviously an example of a much more complex reality, since it is well known that public transport is a particular "good", whose "demand" depends not so much on the price of the ticket, or rather not only on this element, but also on another series of relevant factors, such as the cost of the substitute good, or rather the private means, of the public transport offer (understood as network, availability and accessibility to the service, etc.), all elements that have not been considered in this work as they would deserve an in-depth treatment that goes beyond the purposes of the present analysis.
} 
In principle, from the results obtained it can be concluded that it is possible to implement a price discrimination of the ticket and that, starting from this discrimination, it is legitimate to expect a different response from users, which will automatically be segmented into two areas: one characterized by a narrower need to move at certain times, then willing to pay a higher ticket price, and another that does not have the same needs of the first, which is therefore willing to face a lower price and to make their movements at a different time ${ }^{9}$.

\section{Estimation of consumer surplus}

Using the WTP (Willingness To Pay) methodology, you can estimate the user surplus, which is the maximum amount an individual is willing to pay to receive an improvement or to avoid a loss of their level of well-being. In our case, it is not necessary to estimate the entire demand curve (which would then be to estimate two distinct demand functions, one for users in the "peak" band and the other for the "off peak" band) as an alternative formulation can be used.

In fact, the (inverse) demand function is linear if it is possible to find the value of the constant A (the "suffocation price", different in the two cases "peak" and "off peak") and calculate the area below the two estimated demand functions (see section 5).

In this specific case the estimate can be summarised in Table 5 below.

Table 5: surplus estimate

\begin{tabular}{|c|c|c|c|c|c|}
\hline Cunsomer's surplus es timate & 2019 & 2020 & Cunsomer's surplus estimate & 2019 & 2020 \\
\hline "peak" demand & & & "off peak" demand & & \\
\hline "peak" ante volumes & 36.982 .717 & 37.001 .621 & Volumi "off peak" ante & 55.474 .076 & 55.502 .432 \\
\hline "peak" post volumes & 34.517 .203 & 34.534 .846 & Volumi "off peak" post & 57.767 .004 & 57.796 .532 \\
\hline "peak" ante fare (euros) & 1,5 & 1,5 & "off peak" ante fare (euros) & 1,5 & 1,5 \\
\hline "peak" post fare (euros) & 2,0 & 2,0 & "off peak" post fare (euros) & 1,3 & 1,3 \\
\hline "peak" differential fare (euros) & 0,5 & 0,5 & "off peak" differential fare (euros) & $(0,2)$ & $(0,2)$ \\
\hline$\Delta \mathrm{P} / \mathrm{P}$ & 0,3 & 0,3 & $\Delta \mathrm{P} / \mathrm{P}$ & $(0,1)$ & $(0,1)$ \\
\hline "peak" elasticity & $(0,200)$ & $\overline{(0,200)}$ & "off peak" elasticity & $(0,310)$ & $(0,310)$ \\
\hline Net loss of LPT users & (616.379) & $\overline{(616.694)}$ & Net gain of LPT users & 229.293 & 229.410 \\
\hline ATAC revenue & 17.258 .601 & 17.267 .423 & ATAC leakage/LPT user gain & $(11.553 .401)$ & $(11.559 .306)$ \\
\hline "peak" net variation & 16.642 .223 & 16.650 .730 & "off peak" net variation & $(11.324 .108)$ & $(11.329 .896)$ \\
\hline & & & "off peak" LPT user gain & 11.782 .694 & 11.788 .716 \\
\hline & & & Total net gain of LPT users & 11.166 .315 & 11.172 .023 \\
\hline
\end{tabular}

\section{Source: own elaborations}

The table shows how, with regard to "peak" demand, in the presence of an increase in the fare from 1.5 to 2 euro of the ITT there is a net gain for the producer (i.e. ATAC) of 16.9 million euro and a "dry" loss for consumers/users of 757 thousand euro (in 2019) and 758 thousand euro (in 2020); the algebraic sum of the two quantities amounts to 16.2 million euro.

\footnotetext{
${ }^{9}$ On the magnitude of the effects of fare discrimination in terms of sales volumes of the two respective shares of "peak" and "off peak" demand, it cannot be said with certainty that what was predicted by the evaluation model presented here actually materializes; it can only be said that, according to the available data and the assumptions on which the entire theoretical scaffolding built, a fare discrimination in Rome is possible, just like what is already implemented in other major European capitals.
} 
On the other hand, in the case of "off peak" demand, characterised by a new fare of 1.3 euros there is a net loss for the producer (i.e. ATAC) of 11.8 million euros, while the net gain for users (triangle B) is equal to 483 thousand euros (2020).

In the case of the reduction of the fare from 1.5 to 1.3 euro, however, the loss of the manufacturer transforms into the benefit of users, so that this size, changed in sign, should be added to the incremental surplus for users and the net gain for users "off peak" becomes equal to 12.5 million euros; this value should be subtracted from the "dry" loss of "peak" users, estimated at 758 thousand euros, so that overall as a result of this joint fare maneuver on the ITT (increase "peak" fare and reduction "off peak" fare) the net gain for LPT users amounts to about 11.8 million euros per year (see table 5).

For ATAC, fare differentiation would increase ticket sales revenue and satisfy different user groups in different ways, without affecting regular public transport users (holders of monthly or annual season tickets).

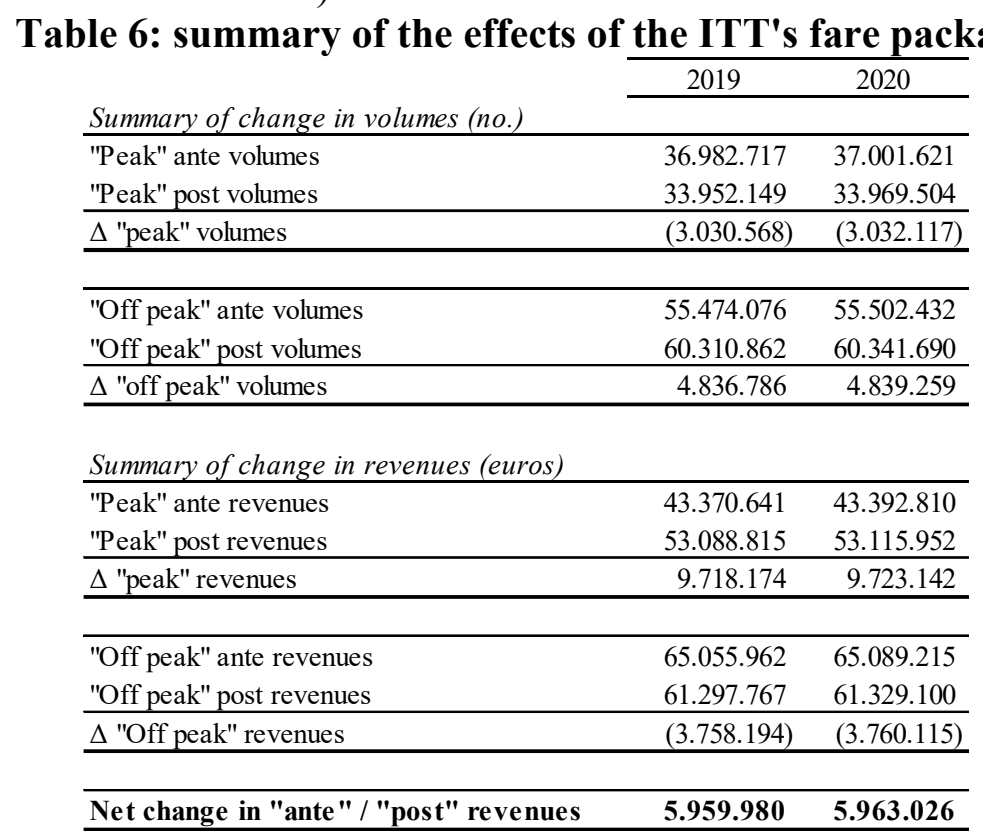

Source: own elaborations

The summary results shown in the table show how, following the implementation of the fare proposal for the ITT presented, and assuming constant sales volumes to 2019 (with a slight growth estimated for 2020) is generated 1) a reduction in sales volumes of peak demand (-3 million shares), 2) an increase in sales volumes of off peak demand (+4.8 million shares); 3) an increase in net sales revenues (ATAC's share) of peak sales (up 9.7 million euros) and 4) a reduction in net sales revenues (ATAC's share) of off peak sales (down 3.7 million euros).

Total effects amounted to $+1.8 \mathrm{mln}$. euros in volumes sold and $+5.9 \mathrm{mln}$. euros in ATAC net revenues.

\section{Estimation of the impacts of tariff differentiation: sensitivity test}

The results obtained were tested to verify the robustness of the estimates and this sensitivity analysis was carried out on the effects of the different distribution of 'peak' and 'off-peak' demand on the total, as one of the crucial parameters is the proportion of the elasticity of 'peak' /'off-peak' demand, which was considered to be about 2. 
The variation of this parameter consequently leads to different 'peak' / 'off peak' elasticity values, with different final effects on sales and revenues.

The test was conducted using empirical results obtained from the Stockholm case study (peak demand elasticity between -0.14 and -0.20 , while for off peak demand the elasticity values are between -0.16 and -0.31 , (see Horn af Rantzien, Rude, 2014).

Using these values and increasing the range of variation down to -0.65 (as proposed by Goodwin) it is possible to obtain a range of values for both incremental volumes and incremental revenues that can be collected in a table: table.:

\begin{tabular}{ccccc}
\multicolumn{2}{c}{ Table 8: effects on sales with different elasticity } \\
\hline \multicolumn{1}{c}{ Average } & "peak" & "off peak" & $\begin{array}{c}\text { Volumes } \\
(2020, \text { units })\end{array}$ & $\begin{array}{c}\text { Revenues } \\
(2020, \text { euros })\end{array}$ \\
\hline$(0,15)$ & $(0,14)$ & $(0,16)$ & $(542.690)$ & 4.289 .138 \\
$(0,27)$ & $(0,20)$ & $(0,31)$ & $(172.674)$ & 4.260 .210 \\
$(0,30)$ & $(0,15)$ & $(0,40)$ & 1.102 .648 & 5.893 .901 \\
$(0,49)$ & $(0,25)$ & $(0,65)$ & 1.807 .142 & 5.963 .026 \\
$(0,65)$ & $(0,33)$ & $(0,86)$ & 2.389 .071 & 6.020 .126 \\
\hline
\end{tabular}

Source: own elaborations

As shown in the table below, the impact on sales revenues is small and always positive, with a net change of about 6 million euros a year (baseline year 2020). The impact on volumes is more variable, with fluctuations between 1.1 and 2.4 million more units sold in the scenario with an elasticity of 0.3 and 0.65 in absolute value, respectively.

If the "peak" and "off peak" elasticities are equal respectively to -0.14 and $-0.16^{10}$, there would still be a positive impact on incremental sales for approximately 4.3 million euros, accompanied, however, by a slight decrease in overall sales volumes.

In summary, as long as the elasticity of demand remains below one, it is possible to differentiate ticket prices, increasing revenues without having an excessive impact on sales volumes. ${ }^{11}$.

Another factor that should be tested is the "peak" and "off peak" demand rates, also deduced from the data on access to metro stations.

In fact, the value of $40 \%$ in favour of "peak" demand could be different, and this variation could affect the results obtained.

Representing on a cartesian diagram on the abscissae axis the \% share of peak demand and on the ordinate axis the variation in ATAC net revenues corresponding to each specific share of peak demand (and consequently off peak) would result in a zeroing of net incremental revenues against a peak share of $20 \%$ (instead of 40), so that this fare design, with differentiated fares of 2 euros and 1.3 euros, and against an average elasticity of the stock at the price of -0.49 (differentiated then in turn according to the two types of

\footnotetext{
${ }^{10}$ The estimates of demand elascicity discussed in this paper are higher, which may depend on several factors, one of which may be the relatively low affinity for local public transport in Rome compared to the Swedish capital, so it is plausible to assume that the elasticities in the Italian case are relatively higher; in Rome, in fact, the use of public transport to make daily trips does not reach the level of other European countries, such as Sweden, since the fraction of trips made by private transport is still very high (given the high rate of motorisation in Rome, more than 800 vehicles per 1.000 inhabitants).

This does not detract from the validity of the estimate made in this work, which, as seen from the sensitivity test illustrated above, maintains its validity even if the proportion between the "peak" / "off peak" elasticity differs from that assumed.

${ }^{11}$ This point deserves particular attention as future studies on this aspect could allow for a refinement of the estimate of this parameter in order to assess with a greater degree of precision the impact on sales of securities following a tariff differentiation such as the one proposed here.
} 
demand), the share of demand "peak" (therefore relatively rigid) should be equal to at least $20 \%$ of the total.

In other words, the data and the figure show that an increase of one percentage point in the share of peak demand in the total results in a corresponding increase in net ATAC revenues of approximately 290 thousand euros per year.

Figure 2: changes in ATAC revenues from ITT sales and \% of peak demand

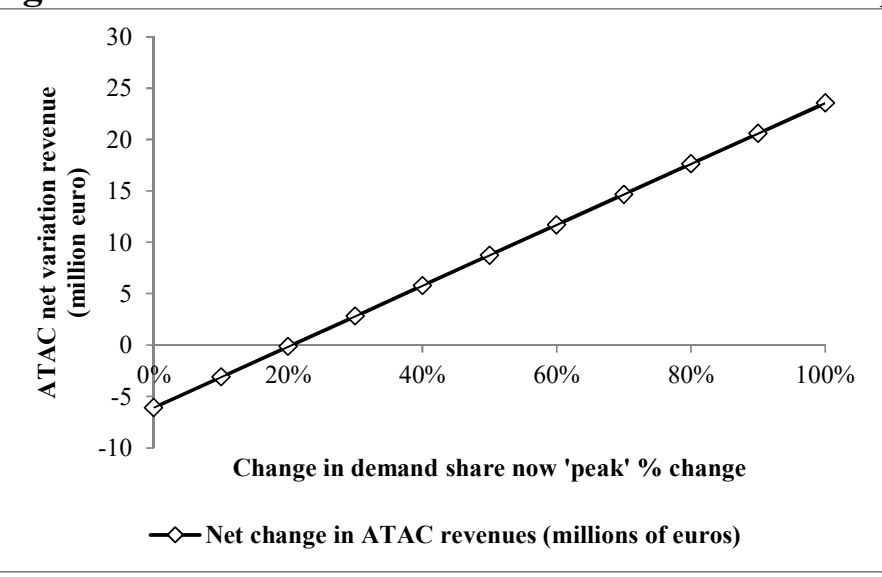

Source: own elaborations

These results are preliminary, based on estimates and hypotheses (first of all the distribution of demand in "peak" and "off peak"), but the results are encouraging and suggest to those responsible for pricing policies in Rome and Lazio to proceed towards more accurate analysis, in order to outline more accurately those parameters (in particular the share of demand "peak" than the "off peak") that affect more the outcome of the assessment.

\section{The costs of implementing the fare proposal}

The implementation of the proposal outlined here is an initial investment expenditure due to the updating of the software of all issuing machines in order to allow the printing and issuing of two different ITT travel documents ('peak' and 'off peak'); in addition, the access gates to metro/railway stations, as well as the validators on board surface vehicles, must also be adapted to detect new tickets.

A first estimate of the investment costs may be as follows:

- adaptation of the issuing software (including Ticket Emitting Machines, TEM) for the production of two separate types of ITT: approximately EUR 5 million;

- software adaptation of the access gates to metro and railways (i.e. validators) to allow the distinction between 'peak' and 'off-peak' ITT (and thus deny access to a user holding an invalid ITT title during that specific time slot, such as an 'off-peak' title during the 'peak' time slot): EUR 3,5 million.

In short, the initial cost of this type of investment would amount to approximately EUR 8,5 million, and is a "one-off" expense, i.e. it would have to be incurred only at the beginning, for the practical feasibility of the tariff change, against an increase in revenue of approximately EUR 5,9 million per year on average.

Finally, it should be considered that, since ITT is part of an integrated tariff system, the Metrebus described above, an overall increase in sales volumes and revenues would also benefit the other Lazio LPT operators, namely Co.Tra.L and Trenitalia, to the extent of their respective shares. 


\section{Conclusion}

The work analysed an alternative proposal to the current tariff system for local public transport in the city of Rome, with particular attention to the Integrated Time Ticket (ITT), which plays an important role in terms of sales volumes and revenues for ATAC.

The new fare proposal is based on the differentiation of the fare according to the time of use of public transport, with a differentiation between the "top" and "soft" bands, so the concept of price elasticity of ticket demand is crucial in order to discriminate between different user bands and the possible reaction of users to an increase/decrease in the fare ( 2 euro "peak" and 1. 3 euro "off peak") has been assessed thanks to a parameter of elasticity of the quantity sold/price of the ticket in question, which allowed a quantification of two different specific elasticities.

In conclusion:

- according to the prevailing literature, it is possible to discriminate between "peak" and "off peak" demand through the application of tariff discrimination models, in fact studies in the literature show the existence of different elasticities for peak and off peak demand (see Horn af Rantzien, V. Rude A. 2014), with values ranging from -0.14 to -0.2 ("peak" elasticity) and from -0.16 to -0.31 or more ("off peak" elasticity), values estimated in contexts different from the Roman one but which confirm at least in part the results obtained in this work;

- for the integrated ticket, given the elasticity of demand to price (estimated at -0.49 , estimated as described at the beginning of this work, based on the change in sales volumes compared to the previous 2012 tariff package), the change in the ticket price could lead to a net increase in ticket revenues (ATAC quota) and also an increase in the overall sales volumes of ITT itself;

- the differentiation between "peak" fares of 2 euros (referring to a share of demand with an elasticity of -0.24) and "off peak" fares of 1.3 euros (referring to a share of demand with an elasticity of -0.65) would allow an increase in revenues (ATAC share), based on the sales forecasts assumed in this study for this ticket in 2019 and 2020, for an amount of approximately 5.9 million euros;

- the fare-adjustement manoeuvre would not affect regular public transport users, i.e. holders of monthly or annual season tickets, since previous ATAC studies have shown that the ITT is mainly used by occasional users, in particular tourists, whose sensitivity to ticket prices is lower;

- variations in the basic parameters of the model, such as a different values of elasticity of "peak" demand compared to "off peak" demand, or a different weight of the incidence of peak versus soft to assess the consistency of peak and off peak demand, do not drastically affect the results obtained, as the net change in incremental revenues for ATAC remains positive.

- the costs connected with the actual implementation of the fare change, i.e. the adaptation of the TEMs and validators at the access points to the subways (or on board surface vehicles) do not seem to be particularly high, so that the coverage of these oneoff costs could already occur in the first year following the implementation of the manoeuvre.

Further analysis could lead in the future to slightly different but also more accurate results, especially in terms of knowledge of the different types of users affected by this measure. 


\section{References}

Article in a journal:

Abrate G., Piacenza M., Vannoni D. (2007), "The impact of integrated tariff systems on public transport demand: evidence from Italy", in Hermes Working Paper, n. 1.

Amisano F., Cassone A., Marchese C: "Trasporto pubblico locale e aree a domanda di mobilità debole in Provincia di Alessandria" Dipartimento di Politiche Pubbliche e Scelte Collettive, working paper n. 183

Asensio J., Matas A., Raymond J.L. (2003), "Redistributive effects of subsidies to urban public transport in Spain”, in Transport Reviews, vol. 23, n. 4 pp. 433-452.

Balcombe R., Mackett R., Paully N., Preston J., Shires J., Titheridge H., Wardman M., White P. (2004), "The Demand for Public Transport: a Practical Guide", TRL-report, TRL593.

Béko J. (2004), "Some evidence on elasticites of demand for services of public railway passenger transportation in Slovenia", in Eastern European Economics, vol. 42, n. 2, pp. 63-85.

Bigerna S, Polinori P. "Analisi economica del settore del trasporto pubblico tra efficienza ed integrazione modale", Quaderni del Dipartimento di Economia, Finanza e Statistica 4. 57, avril 2008.

Bly P., Webster F.V. (a cura di) (1980), "The demand for public transport: report of the International collaborative study of the factors affecting public transport patronage", Transport and Road Research Laboratory, Crowthorne.

Braid, R. M.. (1989), "Uniform versus peak-load pricing of a bottleneck with elastic demand", in Journal of Urban Economics, pp. 320 - 327.

Bresson G., Dargay J.M., Madre J.L., Pirotte A. (2003), “The main determinants of the demand for public transport a comparative analysis of England and France using shrinkage estimators", in Transportation Research Part A, vol. 37, n. 7, pp. 605-627.

Dargay J.M., Hanly M. (2002), "The demand for local bus services in England", in Journal of Transport Economics and Policy, vol. 36, n. 1, pp. 73-91.

de Rus G. (1990), "Public transport demand elasticities in Spain", in «Journal of Transport Economics and Policy», vol. 24, n. 2, pp. 189-201.

Fitzroy F. e Smith I. (1994), "The Demand for Public Transport: Some Estimates from Zurich", International Journal of Transport Economics, n. 21(2), pp. 197-207.

Fitzroy F., Smith I. (1999), "Season tickets and the demand for public transport", in Kyklos, vol. 52, n. 2, pp. 219-238.

Garcia-Ferrer A., de Juan A., Bujosa M., Poncela P. (2006), "Demand forecasts and elasticities estimation of public transport", in Journal of Transport Economics and Policy, vol. 40, n. 1, pp. 45-67.

Garcia-Ferrer A., Poncela P., de Juan A., Bujosa M. (2004), "Monthly Forecasts of Public Transport Integrated Systems: The Case of the Madrid Metropolitan Area", in «Journal of Transportation and Statistics», vol. 7, n. 1, pp. 39-59.

Goodwin P.B., Williams H.C.W.L. (1985), "Public transport demand models and elasticites measures: an overview of recent British experience", in Transportation Research part B, vol. 19, n. 3, pp. 253-259.

Goodwin P.B. (1992), "A review of new demand elasticities with special reference to short and long ram effects of price charges", in Journal of Transport Economics and Policy, vol. 26, n. 2 , pp. 155-170. 
Hanly M., Dargay J.M. (1999), "Bus fare elasticities, a literature review, Report to the Department of the Environment", Transport and the Regions, April, 1999.

Hensher D.A. (1998), "Establishing a fare elasticity regime for urban passenger transport", in Journal of Transport Economics and Policy, vol. 32, n. 2, pp. 221-246.

Hsiao C. (1997), "Statistical properties of the two-stage least squares estimator under cointegration", in «Review of Economic Studies», vol. 64, n. 3, pp. 385-398.

Horn af Rantzien, V. Rude A. (2014) "Peak-load pricing in public transport: a case study of Stockholm”, Journal of Transport Literature, vol.8 no.1.

Kremers H., Nijkamp P., Rietveld P. (2002), "A meta-analysis of price elasticities of transport demand in a general equilibrium framework", in «Economic Modelling», vol. 19 , n. , pp. 463-485.

Littman T. (2004), "Transit price elasticities and cross elasticities", in Journal of Pubblic Trasportation, vol. 7, n. 2, pp. 37-58.

Marabucci, A. (2016), "La domanda e l'offerta di trasporto pubblico locale a Roma: analisi del titolo di viaggio BIT (Biglietto Integrato a Tempo)", in Rivista di Economia e Politica dei Trasporti n.3.

Matas A. (2004), "Demand and Revenue Implications of an Integrated Public Transport Policy: The Case of Madrid" in Transport Review, vol. 24, n. 2, pp. 195-217.

McKenzie R.P., Goodwin P.B. (1986), "Dynamic estimation of public transport demand elasticities: some new evidences", in Traffic engineering and control, vol. 27, $\mathrm{n}$. 2, pp. 58-63.

Paulley N., Balcombe R., Mackett R., Titheridge H., Preston J., Wardman M., Shires J., White P. (2006)," The demand for public transport: the effects of fares, quality of service, income and car ownership", in Transport Policy, vol. 13, n. 4, pp. 295-306.

Piacenza M., Carpani C.,"Sistemi tariffari integrati nel trasporto pubblico locale: un'analisi delle esperienze in Italia" Società Italiana di Economia Pubblica - SIEP, 2004

Tegnér G., Loncar-Lucassi V., Nilsson C., Holmberg I. (1998), "The demand for public transport trips in Stockholm County -a two stage aggregate, non-linear time series model, paper for Economics and Institutions of Transport”, May 25-27, Borlänge, Svezia.

\section{Working paper:}

Abrate G., Piacenza M., Vannoni D. (2007), "The impact of integrated fare systems on public transport demand: evidence from Italy", in «Hermes Working Paper», n. 1.

Amisano F., Cassone A., Marchese C: "Trasporto pubblico locale e aree a domanda di mobilità debole in Provincia di Alessandria" Dipartimento di Politiche Pubbliche e Scelte Collettive, working paper n. 183

Other documents:

ATAC "Indagine sui titoli di viaggio Metrebus Roma e Metrebus Lazio (marzo/aprile 2019): profilazione dei clienti e analisi degli spostamenti, Direzione Marketing ATAC, settembre 2019

\section{Acknowledgements}

The author would like to thank ATAC company for providing the information useful for the drafting of this work. 